\title{
Anti-MMP-9 Monoclonal Antibody GS-5745
}

National Cancer Institute

\section{Source}

National Cancer Institute. Anti-MMP-9 Monoclonal Antibody GS-5745. NCI Thesaurus. Code C105803.

A humanized monoclonal antibody against matrix metalloproteinase 9 (MMP-9), with potential antineoplastic activity. Upon administration, anti-MMP-9 monoclonal antibody GS-5745 binds to MMP-9 and inhibits its enzymatic activity. This results in an inhibition of extracellular matrix protein degradation and, potentially, the inhibition of angiogenesis, tumor growth, invasion, and metastasis. MMP-9, a protein belong ing to the MMP family, plays a key role in the degradation of collagens and proteoglycans; increased activity of MMP-9 has been associated with increased invasion and metastasis of cancer. 